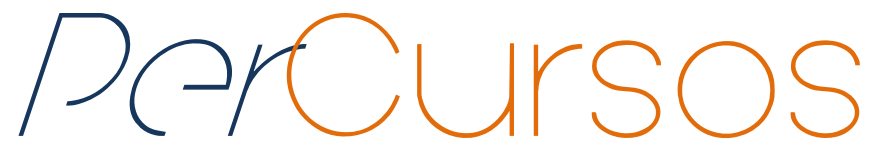

\title{
Por mim ou pelos outros? Representações de gênero e relações de poder em famílias de camadas médias
}

\section{Resumo}

O presente artigo propõe uma análise das relações familiares vinculadas à diferenciação da experiência familiar através de uma perspectiva de gênero. "A Família", como um conceito monolítico originado enquanto uma ideologia burguesa no advento da modernidade, vem sofrendo diversas transformações. Este imaginário tem sido arena de disputas desde 1960 em função da emancipação feminina, do surgimento de novos arranjos familiares e da democratização da intimidade. No contexto das camadas médias brasileiras, trabalho, contracepção e maternidade são ressignificados. Após a realização destas discussões, serão apresentados alguns resultados de pesquisa realizada na cidade de Curitiba-PR, cujo objeto de estudo foram duas famílias heteronormativas de camadas médias com um arranjo hegemônico de convivência, através de entrevistas individuais com seus membros. Observou-se que as relações de gênero e geração nestes espaços passam por questionamentos que levam a uma maior democratização da família, mas ainda se mantêm evidentes representações de gênero tradicionais e binárias.

Palavras-chave: Família. Camadas médias. Relações de gênero. Diferenciação da experiência familiar.

\section{Para citar este artigo:}

AZEVEDO, Mariana Corrêa de. Por mim ou pelos outros? Representações de gênero e relações de poder em famílias de camadas médias. Revista PerCursos. Florianópolis, v. 14, n.27, jul./dez. 2013. p. 154-177.

DOI: $10.5965 / 1984724614272013154$

http: //dx.doi.org/10.5965/1984724614272013154 


\title{
For me or for the others?
}

\section{Gender Representations and power relations in middle- class families}

\begin{abstract}
This article proposes an analysis of family relationships linked to the differentiation of family experience through a gender perspective. "The Family" as a monolithic concept originated as a bourgeois ideology in the advent of modernity, has undergone several transformations. This image has been deconstructed since 1960 due to the emancipation of women, the emergence of new family arrangements and the democratization of intimacy. In a Brazilian middle class context, work, motherhood and contraception are reinterpreted. After completion of these discussions, some results of the research conducted in the city of Curitiba-PR will be presented, and the object of study were two heteronormative middle class families with a hegemonic arrangement of coexistence through interviews with its members. It was observed that gender and generation relations in these spaces undergo questioning that lead to greater democratization of the family, but there are still evident and traditional binary gender representations.
\end{abstract}

Keywords: Family. Middle classes. Gender relations. Differentiation of the family experience. 
Apresentação ${ }^{1}$

A família enquanto instituição social passa por um período denso e complexo de negociações. Surge cada vez com maior visibilidade como uma arena de disputas ligadas a diversos campos, dentre os quais o campo jurídico, os movimentos sociais feministas, gays e transgêneros, as religiões cristãs e os saberes médicos e psicológicos sobre o corpo e o uso da sexualidade. ${ }^{2}$ Este movimento coloca em cheque a padronização da família nuclear burguesa, que se instituiu como modelo dominante desde a emergência da modernidade. Está exposto um processo ainda incompleto de ressignificação do conceito de família, à luz de práticas antes vetadas, invisíveis ou silenciadas.

Mudanças substantivas nos modos de organizar a experiência íntima e familiar têm, portanto, produzido um deslocamento das categorias analíticas de cientistas sociais e pesquisadores da área. Em realidade, desde a década de 1960, com a emergência de uma perspectiva de gênero/feminista dentro e fora da academia, os modos de enxergar o universo privado têm sido revolucionados. Isso incluiu um questionamento acerca das relações de poder encontradas na família tradicional heteronormativa, cuja divisão de tarefas está a favor da manutenção de uma desigualdade naturalizada entre "homens" e “mulheres", diante de seus supostos papeis. A perspectiva das mulheres sobre a vida familiar levou, inclusive, ao questionamento dos modelos teóricos e conceituais disponíveis para pensar as relações de poder na sociedade. Como diz um dos slogans do feminismo, "O privado também é político" (SCOTT, 1990). ${ }^{3}$

A coexistência de uma diversidade de formatos familiares já é estatisticamente mensurável, como mostra a Síntese dos Indicadores Sociais (IBGE) da última década:

\footnotetext{
${ }^{1}$ O presente artigo teve origem no trabalho de dissertação de mestrado, realizada pelo Programa de PósGraduação em Sociologia da Universidade Federal do Paraná, sob a orientação da Prof ${ }^{a}$. $\operatorname{Dr}^{a}$. Miram Adelman, e com a concessão de bolsa CAPES/CNPq no período de sua realização (2009-2011).

${ }^{2}$ Uma das evidências recentes de tais batalhas políticas e discursivas é a ruidosa e controvertida aprovação da União Estável homoafetiva pelo Supremo Tribunal Federal brasileiro, em 5 de maio de 2011.

3 É desta forma que entendemos a produção e manutenção contínuas das relações de poder. "O gênero é então um meio de decodificar o sentido e de compreender as relações complexas entre diversas formas de interação humana. Quando as(os) historiadoras(es) buscam encontrar as maneiras pelas quais o conceito de gênero se legitima e constrói as relações sociais, elas(eles) começam a compreender a natureza recíproca do gênero e da sociedade e as maneiras particulares e situadas dentro de contextos específicos, pelas quais a política constrói o gênero, e o gênero constrói a política." (SCOTT, 1990, p.16, grifos nossos).
} 
No período de 2001 a 2011, houve modificações na distribuição dos arranjos com parentesco, com redução do peso relativo daqueles constituídos por casal com filhos (de 53,3\% para 46,3\%) e, consequente, aumento dos casais sem filhos (de 13,8\% para 18,5\%). Nos arranjos constituídos por mulher sem cônjuge com filhos, os chamados arranjos monoparentais femininos, a PNAD 2011 mostrou uma ligeira redução. Tal padrão de organização dos arranjos está associado à tendência de queda da fecundidade, que, por sua vez, também pode ser atribuída ao desenvolvimento das relações de gênero, no contexto das transformações econômicas e sociais por que passa a sociedade brasileira contemporânea. (IBGE, 2012, p.84)

Em função destas transformações, a intimidade e os "novos" arranjos da vida familiar dos sujeitos na contemporaneidade têm ganhado espaço na pesquisa científica. ${ }^{4}$ Perceber o novo, construindo novos objetos de pesquisa, é uma agenda fundamental das ciências humanas e sociais - uma vez que há aí um compromisso político de construir uma espécie de "analítica da normalização" (MISKOLCl, 2009)

Contudo, os núcleos familiares compostos por casais com filhos, derivam de um padrão cultural fortemente estabelecido e enraizado há mais de um século, que evidentemente também está sujeito a mudanças, fraturas e negociações. Perceber estas mudanças em ambientes "normativos" e "heteronormativos" 6 , como a família conjugal, é uma empreitada que não deve ser posta de lado se temos uma agenda com a redução da desigualdade e a construção da igualdade de gênero na sociedade em que vivemos.

Inicialmente iremos nos deter na construção e crise do imaginário da família burguesa como "A Família" na interpretação da teoria social e através de uma perspectiva de gênero. Num segundo momento iremos pensar sobre como estes são

\footnotetext{
${ }^{4} \mathrm{~A}$ exemplo de alguns trabalhos de pesquisa sobre conjugalidade e parentalidade em relacionamentos não heterossexuais, como a coletânea de Grossi; Uziel ; Mello (2007).

${ }^{5}$ Neste artigo, o autor faz um balanço do surgimento da teoria queer a partir dos Estudos Culturais nos Estados Unidos, e aborda a possibilidade de desconstrução da suposta linearidade entre corpo, desejo e orientação sexual, que possibilitaria um novo olhar para sexualidades tidas ainda como "desviantes". Neste caso, ampliamos o uso do conceito para pensar também nos arranjos familiares não hegemônicos.

${ }^{6}$ Tomamos este conceito de acordo com a definição de Judith Butler (2010), para quem as principais instituições definidoras das categorias de identidade de gênero seriam o falocentrismo e a heterossexualidade compulsória, nas quais operam os processos de significação e construção performática do corpo e das identidades sexuais. A heterossexualidade compulsória teria o poder de conferir certa inteligibilidade e uma coerência imaginária entre sexo, gênero, prática sexual e desejo - minando as possibilidades emancipatórias que se encontram diante de uma espécie de limbo pré-discursivo, o que enfraquece a existência de subversão ao gênero.
} 
recebidos e/ou refutados na constituição das experiências das camadas médias brasileiras, em termos de trabalho, contracepção e maternidade. Na sequência apresentaremos os resultados da pesquisa de campo, que analisa dois casos representativos da família nuclear, conjugal, consanguínea, heterossexual, de camadas médias, cujo vínculo conjugal é de longa data, sem a existência anterior de rearranjos, cujos filhos são coabitantes, e em idade universitária - no sentido de poderem ser entrevistados em pé de igualdade. Optou-se pelo recorte "camadas médias" no sentido de não fazer uma referência direta à sua situação econômica, mas sim a um conjunto de valores ou um ethos que a organiza (SALEM, 2007). Pautamo-nos por entrevistas individuais com cada um destes membros, procurando conhecer suas histórias, criando um mosaico através de suas experiências.

\section{“A Família": construção e desconstrução de um imaginário}

Da perspectiva das ciências sociais, e mais especificamente da sociologia, já é consenso observar que a família é um objeto histórico e não uma instância biológica, encerrada em sua função reprodutiva, evolutiva ou de parentesco. Assim, quando nos referimos à família, estamos falando de uma instituição que responde às particularidades históricas da construção Ocidental moderna - posto que em outras culturas os padrões possuem outros formatos - e que vem sendo problematizada no sentido das mudanças nas relações de gênero e geração. A principal ruptura é a dos papeis tradicionalmente atribuídos a homens e mulheres, significada dentro de um ideal burguês.

De acordo com Edward Shorter (1975), a família enquanto instituição moderna teria como particularidade a sua separação das instâncias tradicionais como a parentela, a comunidade e a tradição, guardada agora por "altas muralhas de privacidade". O fator sentimento teria desalojado a família tradicional em três tempos: o namoro fundado no amor romântico passa a substituir a propriedade pela felicidade individual na conjugalidade; a relação mãe/filho se modifica, uma vez que o bebê ocupa uma nova prioridade a ser assegurada pelo amor materno; e a criação de uma linha limítrofe entre a 
família e a comunidade circundante, uma vez que a família tradicional era muito mais uma unidade produtiva do que uma unidade emocional.

Assim, no âmago desta transformação está o enfraquecimento dos laços externos e o fortalecimento dos laços internos:

Os laços com o mundo exterior enfraqueceram e os laços que ligavam os membros da família uns aos outros reforçavam-se. Foi erigido um escudo de privacidade para proteger a intimidade do lar da intrusão de estranhos. E a família nuclear moderna nasceu no abrigo da domesticidade. Deste modo se infundiu sentimento numa série de relações familiares. $O$ afeto e a inclinação, o amor e a compreensão passaram a tomar o lugar de considerações "instrumentais" na regulação da conduta dos membros da família uns para com os outros. (SHORTER, 1975, p.11)

Na época de sua enunciação, o sentimento era um fator de ruptura e mudança com padrões tradicionais da família extensa. Já sinalizando uma desconstrução deste imaginário, para Michel Foucault (1988) a emergência da família nuclear burguesa está atrelada principalmente a mecanismos de controle da sexualidade, operando como mais um dispositivo regulador. Os dois dispositivos centrais deste jogo seriam aliança e sexualidade. O primeiro se liga mais evidentemente à economia (matrimônio, parentesco e propriedade), enquanto o segundo articula-se com ela de formas numerosas e sutis especialmente através do corpo. É em torno da aliança que a sexualidade se produz, tendo a família o papel de fixá-la e lhe dar suporte. Isso não significa, contudo, que o primeiro dispositivo tenha sido extinto, mas foi sobreposto pelo outro, sugerindo-lhe ainda certo antagonismo. De acordo com a leitura foucaultiana, não é possível pensar a dimensão da sexualidade, normatizada dentro da família, fora de uma analítica das relações de poder na produção dos sujeitos a partir da modernidade.

Para Pierre Bourdieu (2009), a família é a "principal guardiã do capital simbólico", e as mulheres estariam ainda destinadas a administrá-lo. O trabalho doméstico e não remunerado contribuiria para isso, uma vez que seu valor é medido apenas pelo afeto incondicional, ou seja, uma obrigatoriedade perversa que se transforma em "amor fati", que seria o amor pelo destino social. Para este autor, esta fórmula expressa o magnetismo do poder simbólico, que age sem qualquer coação física direta, mas 
encontra sua condição de exercício facilitada pelo imenso trabalho prévio de disposições. É por estar arraigado nas estruturas mentais, lógicas e inconscientes que não se pode esperar superá-lo apenas pela força de vontade consciente.

Outro autor relevante que pensa a desconstrução do imaginário da família burguesa, enfatizando as rupturas no contexto do capitalismo tardio, é Anthony Giddens (1993). Ao tratar das relações de intimidade e das mudanças ocorridas no domínio da sexualidade nas décadas de 1980 e 1990, especialmente no contexto europeu e norteamericano, o autor defende que estamos vivendo uma reestruturação da intimidade no contexto contemporâneo.

A intimidade implica uma total democratização do domínio interpessoal, de uma maneira plenamente compatível com a democracia na esfera pública. [...] As mudanças que atualmente afetam a sexualidade são, na verdade, revolucionárias e muito profundas. (GIDDENS, 1993, p.11)

A democratização da intimidade estaria ligada a novos ideiais de amor que substituiríam o tradicional "amor romântico", como o "relacionamento puro" - vinculado apenas à satisfação emocional de um casal, hetero ou homoafetivo, e não mais à pressupostos e padrões socialmente construídos de unidade familiar e manutenção do lar. Assim, estariam dadas as condições para a construção de parcerias conjugais realmente igualitárias da perspectiva de gênero.

De Shorter (1975) a Foucault (1988), Bourdieu (2009) e Giddens (1993) - passando por matrizes epistemológicas muito distintas - é possível visualizar, em linhas gerais, a construção e desconstrução do imaginário dominante sobre família, sexualidade e gênero no Ocidente. Contudo, é com a crítica feminista que esta desconstrução se radicaliza. Barrie Thorne (1982) problematiza o conceito monolítico de família, a linguagem imutável utilizada para descrever esta unidade, que é ideologicamente construída para criar um mapa funcional de papeis. A família nuclear moderna ao ser tomada como "A Família" contém a chave para a opressão feminina: a exclusão das esferas de poder político e de status social. Sua ideologia extravasa a família e mostra através desta lente o lugar adequado da mulher na sociedade. 
É neste trabalho que a autora aborda a importância de usarmos uma perspectiva como a da "diferenciação da experiência familiar" (THORNE, 1982) para termos uma compreensão densa do universo intrafamiliar e de suas hierarquias. Até a década de 1980, a experiência das mulheres dentro do ambiente doméstico foi distorcida, em especial por ser uma experiência registrada sempre de fora, silenciando a percepção das próprias mulheres. Por esta razão, seria preciso lançar um olhar sobre as estruturas subliminares de gênero e geração no cotidiano familiar.

Mas seria este quadro conceitual adequado para pensar a realidade brasileira? Lia Machado (2001), relativizando a universalização das teorias sobre família no contexto nacional, refuta a dicotomia entre valores individualistas/igualitários em oposição a valores familiares mais tradicionais. Para pensar a nossa sociedade, sem ignorar que a emergência mais generalizada do individualismo produziu inequívocos efeitos na organização da família, há dois pontos a serem notados como diferenças entre as sociedades europeia, norte-americana e a brasileira:

De um lado, nem no Brasil, nem nas nações hispano-americanas, se alcançou o Estado de Bem Estar ou se generalizaram os direitos cidadãos, tal como, por diferentes percursos, o "mundo ocidental desenvolvido" alcançou. De outro, o paradigma cultural ibero-americano que informa a construção social das formas de família, de sociabilidade e da noção de indivíduo apresenta historicamente forte enraizamento católico, em certo grau arabizado. (MACHADO, 2001, p.13)

Essa imagem homogênea e universalizada na qual o amor é o fundamento das relações conjugais e a pedagogia da negociação norteia a educação das crianças não é, portanto, nem teórica nem metodologicamente suficiente para pensar as famílias no Brasil. Machado (2001) indica que nas diversas respostas teóricas à família patriarcal brasileira ${ }^{7}$ há uma notável polarização entre as classes médias portadoras de valores individualistas alinhados a uma esfera global, e as classes populares que tendem a estimar

\footnotetext{
${ }^{7}$ A leitura do pensador social Gilberto Freyre (2006) sobre a formação da sociedade brasileira, no clássico Casa Grande e Senzala, a partir dos engenhos de cana pernambucanos, enfatiza que a miscigenação racial é um elemento constitutivo da nação, uma vez que resume a incorporação de elementos nativos indígenas e africanos sobre a liderança agregadora do senhor de engenho, o patriarca. Sabe-se que havia um projeto político de criar uma narrativa unificadora para o povo brasileiro, que possui uma inegável conotação política.
} 
noções de grupo, reciprocidade e hierarquia. A sugestão da autora para resolver este impasse é a coexistência de um código relacional e de um código individualista que atravessam toda a sociedade, que como uma das matrizes de nossa sociabilidade, faz que hierarquias de gênero no universo familiar apareçam como mais evidentes.

\section{Famílias de camadas médias no Brasil contemporâneo: trabalho,}

\section{contracepção e maternidade}

Há, portanto, uma “flexibilização" dos arranjos de família em jogo na sociedade brasileira contemporânea, que espelham/refletem nas experiências dos indivíduos. Jani Vaitsman (1994), num trabalho pioneiro destas variações, defende que não estaríamos passando por uma crise da instituição família, discurso que ecoa ainda hoje. Mas que a família moderna e hierárquica, construída sobre o imaginário do homem provedor e da mulher doméstica, ou sobre um "individualismo patriarcal”, convive agora com uma pluralidade de arranjos.

A partir de meados dos anos 1960, a expansão das classes médias urbanas e o aumento da participação feminina na esfera pública, em atividades educacionais, profissionais, científicas, políticas e culturais, começam a corroer as bases da família conjugal moderna, que mal havia se firmado entre alguns segmentos da sociedade brasileira. Para as mulheres nascidas em torno dos anos 1950, a participação no mundo público levaria à construção de identidades com critérios de autorrealização diferentes daqueles típicos da dona de casa de classe média da geração anterior. (VAITSMAN, 1994, p.17)

Os fundamentos desta contestação foram vividos em níveis práticos especialmente pela inserção de mulheres na educação, impulsionada pela modernização e estimulando a igualdade e a autonomia, desafiando a estratificação de gênero e a família conjugal. A educação primária deixava de satisfazer as mulheres de classes médias, que começam a buscar vagas nas universidades. A classe média brasileira, cuja gênese se dá a partir dos processos de industrialização mais ou menos a partir de 1955, atinge seu ápice nos anos 1970 - compondo cerca de 20\% da sociedade. Além de agravar os problemas da desigualdade social, essas transformações aceleradas ampliam as 
oportunidades de trabalho para estas mulheres. Deste modo se dá a redefinição da divisão sexual do trabalho, desafiando a dicotomia entre público e privado atribuída segundo o gênero.

Se transformações nas relações de gênero, especialmente no período pós-1960, possibilitam a emergência de ideais conjugais igualitários - que contestam o binarismo hierárquico romântico - estas não solapam radicalmente a existência dentro do lar de certos comportamentos que podem ser definidos como "tradicionais". Embora a dimensão objetiva suscite parcerias igualitárias, a dimensão subjetiva ainda parece induzir à reprodução dos papeis masculino e feminino como opostos complementares.

Estes processos estão invariavelmente alinhados com a emergência de técnicas anticonceptivas e com a tendência de redução do número de filhos, que têm aumentado progressivamente como indicam as estatísticas atuais (IBGE, 2012). Com um número menor de filhos torna-se viável que as mulheres experimentem esta inserção na esfera pública, o que também não acontece sem certas contradições. Ao explorar como foi vivido na esfera privada o controle populacional nos países do terceiro mundo, Joana Maria Pedro (2003) mostra o contraste com a emancipação estabelecida pela pílula no mundo euro-americano.

Historicamente, foi na década de 1960 que se notou em termos estatísticos a queda da natalidade no Brasil, um produto de uma política de Estado internacional e da Igreja católica. Se na Europa deste mesmo período observa-se uma política natalista, o Brasil experimentava um explícito controle populacional. Enquanto na França a pílula só é vendida a partir de 1967, no país ela é comercializada sem entraves desde os anos 1960. Por aqui as informações sobre o novo método apareceram em conjunto com notícias agravantes sobre o perigo da superpopulação mundial. Logo após a Revolução Cubana de 1959 os Estados Unidos passaram a demonizar a América Latina como uma região perigosa para a agitação comunista, as políticas de assistência aos países de terceiro mundo exigiam adesão a certos programas.

Na década de 1970 há um crescimento exponencial do uso da pílula, tanto nas camadas populares que as recebiam gratuitamente pelos programas públicos, como nas camadas médias, que acompanharam a tendência geral de queda de fecundidade no país. 
O principal contraste entre Brasil e França, em uma perspectiva comparada, é que se no segundo os contraceptivos hormonais levam a uma separação inédita entre sexualidade e reprodução ${ }^{8}$, a sociedade brasileira surge como mais um campo de prova para políticas internacionais de controle populacional. Ao analisar a memória de mulheres da geração pílula, nascidas entre 1950-60, Pedro mostra que a contracepção feminina não é lembrada como um resultado das próprias demandas das mulheres brasileiras, como no caso francês, não constituindo parte da memória coletiva feminina como um meio de emancipação.

Com a redefinição dos padrões de família no século $X X$, através da educação/ocupação do espaço público e da contracepção feminina, a maternidade também passa a ser ressignificada. A “escolha da maternidade", como informa Lucila Scavone (2004), é um fenômeno tipicamente moderno, ligado aos processos de urbanização e industrialização, e que atualmente deve ser pensada em termos de globalização, uma vez que esta acelera e difunde padrões de comportamento. As novas tecnologias de controle contraceptivo permitem a muitas mulheres escolher com mais segurança a maternidade, e embora não atinja todas as mulheres da mesma maneira, mostra algumas linhas gerais, como as proles reduzidas e mães que trabalham fora.

Com o desenvolvimento da sociedade industrial e o reingresso das mulheres no mundo do trabalho, coloca-se a questão da "dupla jornada" e a maternidade tende a tornar-se uma experiência mais reflexiva, a exemplo do adiamento da idade de nascimento do primeiro filho por conta da profissionalização das mulheres e investimento prévio em suas carreiras. Isto abre também espaço para a eclosão do "dilema da maternidade."

A escolha da maternidade está ligada a numerosas causas que, isolada ou conjuntamente, se explicam no ponto de interseção do biológico, do subjetivo ou do social: o desejo atávico pela reprodução da espécie ou pela continuidade da própria existência; a busca de um sentido para a vida; [...] o amor pelas crianças; a reprodução tradicional do modelo de família de origem, entre outros. (SCAVONE, 2004, p.175)

\footnotetext{
${ }^{8}$ É o desmembramento destas duas dimensões que Giddens (1993) chama de "sexualidade plástica".
} 
A crítica feminista tem um papel importante na desconstrução do fatalismo biológico da maternidade, como na obra pioneira de Elisabeth Badinter (1992[1980]), que enfatiza que a personagem "mãe" deve ser olhada de maneira relativa e tridimensional. No contexto heterossexual, ela só existe na relação com o pai e com os filhos, e numa equação com seus desejos e aspirações pessoais, que podem ser muito dissonantes com o desejo destes outros vértices do triângulo familiar.

Em síntese, a sociedade brasileira parece acompanhar a tendência de proles reduzidas, escolha reflexiva da maternidade e trabalho feminino, embora marcadas pelas profundas desigualdades sociais existentes no país. E se passamos por um período de transição no sentido de uma busca pela igualdade na responsabilidade parental, a maternidade ainda é pensada como elemento da cultura e identidade femininas. Veremos na sequência como estas transformações e permanências são vividas pelos agentes entrevistados.

\section{Jogo de conflito e manutenção da ordem doméstica e familiar ${ }^{9}$}

Primeiramente nos deteremos sobre a conjugalidade na apresentação dos resultados da pesquisa de campo. Destaca-se um elemento que chamamos aqui de “narrativa simultânea” sobre a história do casamento. Nas duas famílias analisadas, tanto as esposas quanto os maridos falam de maneira muito precisa sobre o momento em que conheceram aquele que parecia "predestinado" para ser seu/sua cônjuge e companheiro/a de vida. Mesmo que seja para se contrapor a noção de "destino", esta é uma palavra comum no léxico dos casais. Mostra-se, portanto, uma dinâmica de reprodução e desconstrução do ideal do amor romântico, ainda um elemento que serve para organizar a experiência dos sujeitos.

\footnotetext{
${ }^{9}$ Como informado em outras seções do artigo, as duas famílias pesquisadas pertencem ao segmento de camadas médias de Curitiba-PR. Para facilitar a leitura serão chamadas de $A$ e $B$, de acordo com o membro de referência (esposa/mãe, marido/pai, filho/filha). A família A é composta por um casal, ambos com 48 anos na data realização da entrevista, há 25 anos casados e com uma única filha (aos 21 anos). A família B é composta por um casal, ela aos 49 e ele aos 47, casados há 29 anos. E três filhos: uma filha, com 25 anos, e dois filhos, com 22 e 20 anos. Estes serão identificados, quando necessário, como Filha B e Filhos B.
} 
Em um dos casos estudados (família A), a esposa e mãe entrevistada explica que não estava com vontade de ir num baile de carnaval no ano de 1984, mas que alguma "força" fez com que ela fosse e ao ir encontrou-se com sua própria fortuna; algo concatenado com a história tal qual contada pelo marido. Nesta entrevista, ela infere que "naquela época as coisas eram diferentes de hoje" - uma impressão compartilhada no senso comum de que os relacionamentos afetivos dos jovens de hoje são marcados por excessos e promiscuidade. Há também um claro sentimento de maternagem pelo marido, pelo ato de "cuidar" - que envolve a criação de um vínculo que irá se tornar um casamento de quase três décadas. Nas palavras dele: "Tinha dito pra mim mesmo que não queria mais aquela vida de bagunça, que ia achar alguém pra sossegar." (Marido A).

Nestas narrativas sobre destino conjugal, como sugerido por Giddens (1993) ao analisar separadamente o amor romântico e o amour passion, observa-se numa das falas:

Então eu digo assim que o nosso relacionamento começou já com uma base sólida de companheirismo, de amizade, não foi aquela paixão arrebatadora, que você "ai, é o homem da minha vida, não vivo sem você...", então ele me conquistou, e eu o conquistei, e ele me conquistou pelo jeito de ser de cada um assim. Um ano depois tava casada, dois anos depois com uma filha. (Esposa A)

Salem (2007) também aborda esta questão da superação do puro erotismo, chamando-a de construção de uma "unidade com dois". Quando Scavone (2004) aponta para a tendência da "maternidade reflexiva", ou seja, embasada em uma escolha racional acerca do ser ou não ser mãe. Para a entrevistada, o fenômeno da maternidade reflexiva não chega a se estabelecer de modo consciente e explícito, e parece que torna-se mãe em função de um curso natural da vida.

As narrativas simultâneas e a ideia de que o casamento entre eles é muito mais do que uma casualidade, parece constituir o núcleo central da história do casal e algo nodal para a sua manutenção. Também a linearidade súbita da construção da vida conjugal está aqui presente, posto que construíram suas famílias na década de 1980. E de maneira correlata com a noção de "mãezona" da esposa, cabe aqui ao marido aparecer como alguém que finalmente encontrou a cara metade que vai fazer com que ele tenha alguma coisa mais sólida na vida, além da "bagunça" dos anos de juventude. Na outra família (B), 
mesma dinâmica: há uma primeira aproximação, que leva ao namoro, em sequência ao casamento e ao nascimento dos filhos. Assim, também a escolha reflexiva da maternidade não parece ter assumido forma tão delineada.

Em segundo lugar, sabemos que as relações conjugais na atualidade estão mais sujeitas do que nas gerações anteriores ao fator satisfação emocional dos parceiros, que como discutido geram padrões familiares agora subordinados a uma maior democracia nas relações íntimas (GIDDENS, 1993; VAITSMAN, 1994). Um equilíbrio instável sujeita as relações amorosas então, uma vez que o casamento não é mais uma instituição indissolúvel como outrora - a aprovação do divórcio no Brasil ocorre em 1977. Mas que elementos geram conflito na vida do casal? E como estes casais resolvem seus problemas em termos da manutenção do casamento (reconciliação contínua)? Ainda na família A, a esposa encarou uma graduação de pedagogia depois de adulta e com a filha já adolescente, o que começou a gerar conflitos no casamento. O fato de a mulher estar perseguindo seus objetivos profissionais e de carreira aparecem como motivos de divergência entre o casal, incitando uma “fase negra". Nas palavras dela:

Quando eu fiz a faculdade e eu trabalhava, eu tinha uma profissão e começamos a ter certa dificuldade no relacionamento, porque eu comecei a exigir dele... Que ele fizesse alguma coisa por ele, não por mim. Não pela família, mas por ele. Porque, o quanto aquilo tinha feito bem pra mim e ele começou a se sentir mal, tanto que o que nos uniu quase que nos separou, porque se quando a gente começou a namorar a carência dele nos uniu, agora esse lado fraco dele, que daí ele achava "a [minha esposa] ganhava mais do que eu, ela tem uma profissão, a [minha esposa] é realizada, ela tá bem e eu sou o quê? Nada." (Esposa A)

Esta não é nenhuma novidade sociológica. Quando mudanças sociais promovem a possibilidade de subversão dos papeis tradicionalmente associados ao masculino como provedor e ao feminino como cuidador: ou os papeis familiares funcionalistas do homem instrumental/mulher expressiva, isso pode gerar problemas de acomodação. Vaitsman (1994) usa a expressão de "ambiguidade sociológica da família", uma vez que esta instituição tem que dar conta de amortecer cotidianamente processos opostos de individualização e solidariedade. 
Neste período de divergências marido e esposa foram apresentados a um curso de casais, que frequentaram anos a fio, chegando inclusive a assumir postos na coordenação do mesmo. O marido é enfático ao reconhecer o curso como pedra fundamental para a "saúde do relacionamento". Ao que aparece na narrativa do casal, o curso os instrumentaliza para "saber como brigar”. Divergências estão longe de não existirem no casamento, e ambos admitem isso com naturalidade. Mas através do exercício de reflexão em um grupo, os problemas se mostram superáveis. No outro casal, o mesmo esquema de parceria opera na resolução diária de problemas e conflitos.

Por último, uma das principais fontes geradores destes conflitos é a manutenção do lar, também pedra de toque na construção e desconstrução das identidades de gênero entre esposos/pais e filhos. Como se organizam as tarefas domésticas, pensadas pelo olhar do casal e também dos filhos? O conceito de divisão do trabalho é um dos mais antigos da tradição sociológica, e passa a ser problematizado por militantes e pesquisadoras feministas em meados do século XX quando estas buscam compreender fatores políticos subjacentes a uma divisão sexual do trabalho tomada como natural.

No caso do Brasil contemporâneo, Araújo e Scalon (2005) enfatizam que embora mudanças substantivas tenham ocorrido neste processo de recolocação de mulheres no mundo do trabalho, o ritmo das mesmas é ainda muito lento. Elas apontam que as percepções de homens e mulheres sobre trabalho/família vão em direção a uma cultura mais igualitária, mas práticas de caráter mais tradicional persistem em meio a este processo.

Nos dois casos pesquisados é bastante naturalizado o julgamento de que as tarefas domésticas competem à mulher/esposa e mãe - e aqui usamos intencionalmente essa tríade que se vê também misturada na prática. Esta naturalização compete a todos os membros da família: às mulheres, aos homens e aos filhos. E é uma fonte aparentemente inesgotável de conflito. Possivelmente um sintoma de transformações silenciosas nas relações de gênero, nem sempre já elaboradas ou resolvidas em termos de novas práticas mais democráticas. 
Nas palavras do marido da família $A$, respondendo à pergunta de como se divide a rotina de organização doméstica na sua família:

É igual, às vezes eu não tenho paciência pra limpar a casa, ela quer limpar, eu meio brabo vou e ajudo. Eu acho que não é justo. Desde que a gente casou eu nunca tive esse tipo de preconceito. Não é porque eu moro com uma mulher que a mulher tem que fazer tudo dentro de casa e eu ficar vendo televisão. Negativo, eu sujo igual, eu uso igual, eu gasto igual, porque que eu vou ter que deixar ela trabalhar, ser empregada e eu ficar no meu bem bom o tempo inteiro? Tem muita gente que é assim, né? (Marido A)

Aqui vemos a enunciação de uma dinâmica mais igualitária e o questionamento do gênero binário, não encontrada no outro núcleo. Quando analisamos a relação com a única filha do casal, ambos concordam com a sua falta de organização e participação nas tarefas domésticas. No discurso da mãe:

Tá barato esse hotel né? Preciso aumentar o valor do hotel, porque tá muito barato". Porque ela vem pra casa pra dormir, aí final de semana ela vem pra casa pra se arrumar; agora com namorado então não para em casa, ou quando ele não tá aqui, ela tá lá. (Esposa A)

A expressão "mora em um hotel" é muito comum na descrição de como os jovens de camadas médias de hoje vivem, sempre atarefados com suas obrigações universitárias, estágios, outros cursos e com o tempo gasto no lazer com amigos e/ou namorados. Para a filha, "Eu sou o extremo do ruim e ela o extremo do bom. Nem um nem outro é bom. Eu tinha que ser mais organizada e ela menos organizada" (Filha A). Ela se percebe como desorganizada, mas enfatiza que não o faz de modo proposital e sabe que esta característica de sua personalidade/geração - uma vez que é tomada como característica desta geração de jovens - é o principal catalisador de conflitos com o núcleo familiar e, principalmente, com a mãe.

No outro núcleo pesquisado, a mãe/esposa parou de trabalhar aproximadamente aos 40 anos e teve seu estatuto modificado - de mulher trabalhadora para mulher da casa. Junto disso crescem as exigências em torno do seu desempenho doméstico, o qual ela realiza com destreza, amor fati, já que afirma: “eu fico lidando nessa casa o dia 
inteiro" (Mulher B). Seu marido trabalha o dia todo e afirma que eventualmente ajuda a "guardar uma loucinha".

Diferentemente de outros contextos sociais, os filhos ingressam no meio universitário e no mercado de trabalho como uma fonte de experiência e formação profissional visando uma boa colocação. ${ }^{10}$ Não foi percebido em nenhum momento nos universos pesquisados qualquer exigência de que a sua (mesmo que pequena) renda seja revertida para a família, sendo usada de forma individual e ainda, em alguns casos, completada com uma mesada generosa. Da forma sagaz como uma mãe percebe, "A gente cria os filhos pra não ajudar, pra não dar tempo." (Mãe B). Volta a aparecer aqui a noção da mãe protagonista e os demais, coadjuvantes, que dão uma "ajudinha". Na perspectiva de um dos filhos:

A minha mãe faz quase tudo, $90 \%$ das coisas. O que eu faço, eu e o meu irmão, é guardar a roupa, de vez em quando tirar a roupa do varal, de vez em quando arrumar a cama, bem de vez em quando. Daí de vez em quando arrumar o quarto. Enxugar a louça às vezes, botar a mesa, ajudar a fazer a comida, uma vez ou outra. Mas isso que eu digo é bem raro, é bem quase nunca. (Filho B)

Nota-se a naturalização do papel feminino aqui, e a tentativa do filho de mensurar o quanto realmente faz no âmbito das tarefas domésticas, até concluir que é 'quase nada, quase nunca'. Mas os filhos são também capazes de perceber que a mãe está operando num modo automático e frenético, ao limpar e cuidar da casa de modo intensivo. Afirmam que dizem inclusive para a mãe ir descansar, mas que ela não os ouve.

Com relação ao duplo padrão de gênero, a filha da família mais numerosa, constata com indignação que ela, por ser mulher, sempre foi mais cobrada do que os irmãos homens. Diz:

O que eu sinto é que a minha mãe é muito machista. Então tem algumas coisas que eu ficava muito puta [antes de se sair de casa]. Desde que eu sou pequena, é a mulher que tem que limpar a casa, é a mulher que tem que ajudar. $\mathrm{E}$ os meus irmãos quase nunca fizeram nada assim. Depois

\footnotetext{
${ }^{10}$ Este quadro varia muito em camadas populares. Como mostram os pesquisadores Ozella e Aguiar (2008), nas classes $\mathrm{D}$ e $\mathrm{E}$ é comum que os adolescentes ingressem 'precocemente' no mercado de trabalho (meninos) e que operem ativamente na realização das tarefas domésticas e cuidado dos irmãos menores (meninas). Esta variação gera inclusive angústia diante da não identificação com a imagem do jovem "cucafresca" de classe média.
} 
que eu fui pra faculdade mudou um pouco, porque eu não estava em casa, ela precisava de ajuda, daí ela chamava um dos dois. Mas antes era eu, eu, eu. E isso era um dos motivos de briga. Os meus irmãos não tiram o prato da mesa, sabe? E eu que tenho que tirar. (Filha B)

Saltam aos olhos nessa passagem as representações tradicionais de gênero, quando a filha diagnostica que sua mãe é "muito machista”, por considerar que apenas as mulheres precisam desempenhar esse papel de limpadoras e organizadoras da casa - que se localizam não só no âmbito conjugal, mas também em termos geracionais. E, ao mesmo tempo, o olhar crítico que cria a condição de sua superação.

\section{Relações de gênero, sexualidade e dilemas a partir da autonomia dos filhos}

Num dossiê recente sobre sexualidade e gênero na juventude, as autoras Heilborn, Aquino e Knauth (2006) explicam por que discutir autonomia e sexualidade conjuntamente:

A sexualidade se apresenta na juventude como uma das esferas de aquisição de autonomia individual em relação à família de origem. A construção desse espaço privado pressupõe um aprendizado sobre relacionamento afetivo e sexual. Os modos de interação sexual derivam de prescrições culturais que mudam conforme o tempo histórico, o meio social e o gênero. (Idem, p.1362)

Primeiramente, nas duas famílias foi encontrado um quadro muito claro de “superproteção" parental, o qual se expressa de maneira mais aguda pelas mães, mas também assola o comportamento dos pais (homens) diante de seus filhos. Dois aspectos a serem salientados: o primeiro é que o "amor" é considerado o motivo pelo cuidado, muitas vezes sentido como exagerado, com a mobilidade dos filhos. O segundo é relativo à cultura do medo contemporânea, que acomete particularmente a juventude, representada como sujeita a inúmeros riscos (drogas, violência, DST/AIDS e gravidez).

Como afirma uma das entrevistadas: "A minha mãe é muito superprotetora; se eu saio, duas horas da manhã ela liga: “Cadê você?!” (Filha A). De acordo com o pais: “A gente tenta proteger. Talvez um pouco demais, mas o que a gente tem tentado é 
proteger ela.” (Pai A). Ou então, nesta outra passagem: “Ai, a minha mãe é muito galinha choca que tem que ficar com os pintinhos perto assim, ela é muito, como é que eu vou falar, até meio dominadora assim, sabe?" (Filha B).

No que tange à sexualidade, o quadro é parecido com o da divisão das tarefas domésticas. Vale citar pesquisa quantitativa e abrangente sobre juventude e sexualidade (CASTRO, SILVA e ABRAMOVAY, 2004), na qual a iniciação sexual é de fato representada como um terreno de afirmação da autonomia dos jovens. As pesquisadoras observam que a menor durabilidade dos relacionamentos amorosos entre os jovens não significa que eles não possam levar a vínculos mais estáveis (o "ficar" como ponte para o “namorar”, mas também como abertura para experiências menos rígidas). Também notam que pais e educadores se mostram assíduos defensores do duplo padrão de moralidade, o que acaba sendo reproduzido também no discurso dos jovens.

A perda da virgindade, especialmente das mulheres, é sentida como "perda" mesmo pelas mães e mulheres, já que indicaria simbolicamente que a filha é dona das suas escolhas. Como aponta a seguinte passagem:

Ela chegou e falou "Mãe, precisamos conversar." Aí quando ela falou "Precisamos conversar", eu falei "Opa, já vi esse filme". Quando ela tinha quatorze anos me disse que tava namorando agora com dezenove... né? [...] Na hora foi um sentimento de "perdi". "Perdi a minha filhinha". Tipo "ela não depende mais de mim". Aquela menina que eu sempre mandei, que eu sempre fui a sargentona, que eu comandava, que eu né, tinha como; agora não mais, que agora ela estava diante de uma situação que ela era uma mulher, que ela estava me mostrando que ela era mulher. (Mãe A)

Na sequência ela fala com a filha sobre os cuidados médicos que considerava necessários, cuja responsabilidade foi assumida pelo pai.

Eu fui no ginecologista com ela. Eu, eu levei ela. Não entrei na sala, lógico. Mas fui até a porta, a atendente viu, ela entrou sozinha, saiu, acho que foi a melhor coisa, porque se fosse a mãe, a mãe ia entrar junto, né? la ficar falando, tudo que é resposta da filha é a mãe que ia falar. Ela saiu toda contente, "ah, tem que comprar pílula". Paramos, comprou, até 
hoje toma a mesma pílula, né? Então foi legal, eu me senti bem, me senti bem. E eu tenho certeza que ela se sentiu apoiada. (Pai A)

Embora os pais tenham relatado tranquilidade diante da situação da perda da virgindade da única filha e dos encaminhamentos que se fizeram necessários, a percepção desta com relação ao momento é diferente. Segundo ela, sua mãe ficou muito nervosa e pediu que ela não tivesse mais relações sexuais com o namorado. E diz: "Como ela surtou surtado, eu continuei fazendo e não contei mais." (Filha A). Este é um dos pontos da pesquisa onde a "diferenciação da experiência" se torna mais evidente.

Na outro caso estudado, a iniciação sexual da filha mais velha é narrada pelo casal de forma quase pitoresca, uma vez que eles passaram meses separando a filha do namorado nos cômodos da casa, pois embora ele dormisse na casa da família, a regra era que dormissem em quartos separados.

Então, ela sofreu bastante. Porque eu te digo, que a gente controlava muito, e daí desde um dia ela pegou e foi embora lá pra longe, lá pro outro lado do mundo [morar em outro país]. Eu acho que as pessoas acabam fazendo isso, temem mais pelas mulheres né, pensam que... os meninos ou se viram melhor, ou que pra eles é mais tranquilo, não ficam difamados, digamos assim. (Mãe B)

Aqui podemos perceber a manutenção do duplo padrão e a preocupação da mãe com a "fama" da filha, posto que os demais filhos são homens. Para esta, segue a mesma indignação com relação às tarefas do lar: “Meu irmão que está namorando há dois meses pode dormir com a namorada, eu que estou há, na época, tipo seis anos não posso sabe?" (Filha B). De acordo com seu relato, os dois irmãos, mais novos 3 e 5 anos tiveram as vias de acesso à dormir com as namoradas em casa muito facilitadas por duas coisas: ela ser a mais velha e "desbravadora" e eles serem homens. O relato do pai está alinhado com o da mãe, pois compactua com a noção de que as mulheres tem que ser mais reservadas, posto que "eles preferem as mais reservadas" (Pai B) - embora ele não se sinta tão cobrado pela manutenção da reputação da filha. Curioso também é que se autoclassifica como "liberal" deste ponto de vista. Cabe ainda mais uma passagem na qual a filha rememora da orientação dada pelo pai: 
E aí quando, bem no começo, que eu comecei a namorar, nem estava pensando nisso, o meu pai chegou um dia assim, sentou do meu lado "então, eu preciso falar umas coisas pra você" e aí começou a falar umas coisas assim que eu fui ficando roxa, sabe? Ele falou "porque você sabe como homens são" e aí ele falou bem assim "e nunca acredite na história só a cabecinha". "Pai, chega, não quero escutar você falando essas coisas..." Muito engraçado assim. Mas eu acho que eles não sabiam muito como fazer esse approach assim, sabe? (Filha B)

Nesta passagem as colocações do pai reforçam mais uma vez o duplo padrão, no conselho de que precisa ter cuidado, que os meninos são malandros e não controlam seus instintos sexuais - tarefa que compete, portanto, às mulheres, uma vez que precisam manter-se "reservadas".

Por último, ainda gostaríamos de analisar o momento de crise materna quando da saída desta primeira filha de casa. A mãe diz, com visível melancolia, os olhos profundos: "a gente fica triste quando o filho vai embora" (Mãe B). Cabe aqui emprestar uma expressão da psicologia e da psiquiatria, que hoje já é patrimônio do senso comum. A "síndrome do ninho vazio" surge como uma das patologias do mundo moderno, especialmente em mulheres de meia idade que experimentam a saída de casa dos filhos que atingem a idade adulta e a lida com a morte ou a doença dos pais idosos. Este quadro parecer definir bem o sentimento de perda que atinge em particular esta mulher que cedeu o relato mais emocionado do trabalho de campo.

Ao ter seu estatuto modificado após interromper a vida profissional para cuidar da mãe idosa, a sua identidade fica comprometida uma vez que passa os dias lidando com a casa, perdeu sua vaidade e sente-se incompleta sem os filhos por perto - uma vez que estes estão se dividindo em inúmeras atividades de lazer e investimento no início de suas carreiras profissionais. Como a sua identidade feminina está ancorada fortemente nos signos como o cuidado da casa e dos filhos, a saída em "um dos seus" gera uma desestruturação profunda da experiência vivida: "Não sei como é que vai ficar a vida da gente, né? Como diz, os filhos a gente cria pro mundo... cria pro mundo. Então eles nunca vão ficar perto das asinhas da gente, né?" (Mãe B). Questiona-se sobre o sentido da vida, 
uma vez que se doou tanto que, afinal, a ambiguidade restante é se a vida é "por mim ou pelos outros?"

\section{Considerações finais: ainda entre permanências e transformações}

Com base nas discussões realizadas e na apresentação dos resultados da pesquisa de campo, ainda podemos notar uma clara tensão entre a democratização das relações de gênero e a reprodução de padrões hierárquicos na família, entrecortados por estruturas de gênero e geração.

É possível perceber como as disposições identitárias estão ainda ligadas à construção do gênero binário e como estas organizam as experiências subjetivas dentro da família, potencializando a existência de conflitos interpessoais - precisamente porque tal construção binária da identidade é sentida como incômoda.

Portanto, embora a ruptura destes padrões em busca de uma maior igualdade prática - como na divisão das tarefas do lar e nas responsabilidades parentais - ainda esteja longe de ser concretizada (até porque permanece como ideal), podemos perceber as condições prévias para que esta busca continue, embora não sem a existência de dilemas entre a fragmentação e a segurança que a família produz, ou, dito de outro modo, dilemas entre os processos de individualização e solidariedade que fazem parte da inerente ambiguidade sociológica desta instituição.

\section{Referências Bibliográficas}

ARAÚJO, Clara; SCALON, Celi. Percepção e atitudes de mulheres e homens sobre a conciliação entre família e trabalho pago no Brasil. In: ARAÚJO, Clara; SCALON, Celi. (Org.) Gênero, família e trabalho no Brasil. Rio de Janeiro: FGV, 2005. p. 15-77.

BADINTER, Elisabeth. Um amor conquistado: o mito do amor materno. São Paulo: Círculo do Livro, 1992. 
BOURDIEU, Pierre. A dominação masculina. Rio de Janeiro: Bertrand Brasil, 2009.

BUTLER, Judith. Problemas de Gênero: feminismo e subversão da identidade. Rio de Janeiro: Civilização Brasileira, 2010.

CASTRO, Mary Garcia; ABRAMOVAY, Miriam; SILVA, Lorena Bernardete. Juventudes e sexualidade. Brasília: UNESCO Brasil, 2004.

FOUCAULT, Michel. História da sexualidade I: A vontade de saber. Rio de Janeiro: Edições Graal, 1988.

FREYRE, Gilberto. Casa-grande \& Senzala: formação da família brasileira sob o regime da economia patriarcal. São Paulo: Global, 2006.

GIDDENS, Anthony. A transformação da intimidade: sexualidade, amor e erotismo nas sociedades modernas. São Paulo: Editora UNESP, 1993.

GROSSI, Miriam; UZIEL, Anna Paula; MELLO, Luiz (Org). Conjugalidades, parentalidades e identidades lésbicas, gays e travestis. Rio de Janeiro: Garamond, 2007.

HEILBORN, Maria Luiza; AQUINO, Estela M. L. e KNAUTH, Daniela Riva. Juventude, sexualidade e reprodução. Cadernos de Saúde Pública, v.22, n.7, p. 1362-13632006. Disponível em: <http://www.scielo.br/pdf/csp/v22n7/01.pdf> Acesso em: 20 set 2013.

IBGE. Síntese dos Indicadores Sociais: Uma análise das condições de vida da população brasileira. 2012. Disponível em:

<http://http.ibge.gov.br/Indicadores_Sociais/Sintese_de_Indicadores_Sociais_2012/SIS_20 12.pdff> Acesso em: 19 set 2013.

MACHADO, Lia Zanotta. Famílias e individualismo: tendências contemporâneas no Brasil. Interface (Botucatu), Botucatu, v. 5, n. 8, 2001. Disponível em: <http://www.scielo.br/scielo.php?script=sci_arttext\&pid=S141432832001000100002\&lng=en\&nrm=iso > Acesso em: 19 set 2013.

MISKOLCI, Richard. A Teoria Queer e a Sociologia: o desafio de uma analítica da normalização. Sociologias, Porto Alegre, ano 11, n.21, jan./jun.. 2009, p.150-182.

OZELLA, Sérgio; AGUIAR, Wanda Maria Junqueira. Desmistificando a concepção de adolescência. Cadernos de Pesquisa, São Paulo, v. 38, n. 133, p. 97-125, jan./abr. 2008.

PEDRO, Joana Maria. A experiência com contraceptivos no Brasil: uma questão de geração. Revista Brasileira de História, São Paulo, v.23, n.45, p.239-260, 2003. Disponível 
em: < http://www.scielo.br/scielo.php?script=sci_arttext\&pid=S0102-

01882003000100010\&lang=pt> Acesso em: 19 set 2013.

SALEM, Tania. O casal grávido: disposição e dilemas da parceria igualitária. Rio de Janeiro: Editora FGV. 2007.

SCAVONE, Lucila. Maternidade: transformações na família e nas relações de gênero. In: Dar e cuidar a vida: feminismo e ciências sociais. São Paulo: UNESP, 2004. p.171-186.

SCOTT, Joan. Gênero: uma categoria útil de análise histórica. Educação e Realidade, Porto Alegre, v.16, n.2, p.5-22, 1990.

SHORTER, Edward. A Formação da Família Moderna. Lisboa: Terramar, 1975.

THORNE, Barrie. Feminist Rethinking of the Family: An Overview. In: THORNE, Barrie; YALON, Marilyn. Rethinking the Family: Some Feminist Questions. Nova Iorque: Longman, 1982. p.1-24.

VAITSMAN, Jeni. Flexíveis e Plurais: identidade, casamento e família em circunstâncias pós-modernas. Rio de Janeiro: Rocco, 1994.

Recebido em: 20/09/2013 Aprovado em: 18/11/2013 